\title{
Exploration and Construction of the Interdisciplinary Talent Training System of Digital Media Art Specialty
}

\author{
Wencai Lin ${ }^{1, *}$ Yuyuan Zhou $^{2}$ \\ ${ }^{1}$ Fuzhou University of International Studies and Trade, Fuzhou, Fujian, China \\ ${ }^{2}$ Ningde No.1 High School, Ningde, Fujian, China \\ *Corresponding author. Email: linwencai@fzfu.edu.cn
}

\begin{abstract}
This article will focus on the digital media art specialty, discuss the social needs and characteristics of interdisciplinary talents of digital media art specialty under the system of interdisciplinary training, deeply analyze the experimental exploration and construction of training system of interdisciplinary talents of digital media art specialty against the background of social and economic development, and finally refine the specific talent training models, such as the training system of "science, technology and art innovation laboratory" and the training system of "interdisciplinary cooperation course". It is hoped to provide a reference for the cultivation of interdisciplinary talents in digital media art specialty in relevant applied undergraduate universities.
\end{abstract}

Keywords: Interdisciplinary talents, Interdisciplinary courses, Digital media art major, Undergraduate colleges.

\section{INTRODUCTION}

"The 13th five-year plan for the development of national strategic emerging industries" issued by the State Council proposes to promote the development of cultural and creative design industry with digital technology and advanced concepts, and promote the deep integration of culture, technology and industry. In order to adapt to the new development of digital cultural innovation industry, it is necessary to strengthen the construction of interdisciplinary courses and practical exploration of training mode of compound talents in digital media art specialty. Through the collection and analysis of data, this paper deeply discusses the characteristics and social needs of compound talents under the interdisciplinary training system of Chinese digital media art specialty. From the new perspective of the

*Funds: This paper is supported by the phased achievements of General Project of 2020 Fujian Education Research of Young and Middle-aged Teachers (Social Science) — "Research on the Management Policy of University Scientific Research Funds under the Background of the New Era" (JAS20300); 2020 School-level Fund Project of Fuzhou University of International Studies and Trade — "Interaction Design" (2018KYTD-08). interdisciplinary of science and technology and art, this paper refines the training system of "science and technology and art innovation laboratory" and the training system of "inter-college cooperation course". Through the experimental exploration and construction of the training system of interdisciplinary talents of digital media art specialty, it is hoped to provide reference for the training of interdisciplinary talents of digital media art specialty in relevant application-oriented universities.

\section{THE MEANING AND CHARACTERISTICS OF INTERDISCIPLINARY TALENTS}

The interdisciplinary refers to the interdisciplinary integration of multi-disciplinary courses, by which a new construction of disciplinary knowledge is formed. The compound refers to combination and synthesis. Also, it refers to the synthesis of a variety of professional knowledge, a variety of professional skills, and a variety of thinking. Interdisciplinary talents refer to those who have basic knowledge and skills of many 
subjects. Interdisciplinary talents can be cultivated through "interdisciplinary + compound" learning of various majors. The talents can not only study various disciplines independently, but also blend and synthesize various disciplines. They can link up the theory and knowledge of multiple disciplines and form new theoretical thinking mode and new working methods. Digital media art specialty is the core of interdisciplinary teaching. In the process of teaching, students majoring in digital media art will learn video, animation, programming, performance, project management and other aspects. Interdisciplinary learning is just what digital media art specialty needs. Digital media art specialty pays more and more attention to the integration of art and technology, and the works of art will also reflect a kind of discipline integration.

Interdisciplinary talents have the following characteristics: firstly, interdisciplinary talents are characterized by mastering the knowledge of interdisciplinary majors. On the one hand, students have a wide range of basic knowledge and professional theory. In terms of knowledge structure, interdisciplinary talents can achieve the leap-type learning of natural science and social science, have basic theoretical knowledge of two or more disciplines, and extensive professional knowledge reserve is the basis of interdisciplinary and comprehensive knowledge. On the other hand, it is the integration and infiltration of multiprofessional knowledge. The integration and refinement of basic theoretical knowledge of humanities, society, science and other disciplines by interdisciplinary talents is the main characteristic and important symbol of interdisciplinary talents' ability. The integration of interdisciplinary knowledge not only helps to solve the development problems faced by the major, but also makes it easier to create new fields and new ways of work, which will be reflected in the innovation ability. This is the thinking compound on the basis of interdisciplinary knowledge. In addition, the main characteristics of interdisciplinary talents are also reflected in the combination of theory and practice. While affirming the interdisciplinary innovative thinking, it is necessary to pay attention to the recombination of skills, that is, the comprehensiveness of ability. The integration of a variety of professional basic knowledge is conducive to the formation of practical ability. The thinking mode and working method of the abilities of various disciplines are not simply added, but a kind of interaction between different professional knowledge and learning from each other to form a new thinking mode and effective practice method. Knowledge and skills are not in the state of attending to one thing and lose another, but beyond the original knowledge system and skill system. On the basis of giving full play to the advantages of different professional knowledge, a new construction mode is formed, and this mode is innovative. Interdisciplinary talents can achieve the transcendence of original professional knowledge and practice in the integration of different professional basic knowledge and skills, and can think about problems through an "interdisciplinary + compound" thinking mode, and propose an effective solution. Human creativity will also be integrated and burst in this process. Interdisciplinary talents are persons with innovative spirit and practical ability, and they are talents with penetrating ability that grow up with the needs of social and economic development. For example, the talent training of digital media art specialty mainly involves the exploration and construction of basic knowledge of many disciplines. These knowledge bases are various, both aesthetic and scientific. Beauty and programming are interwoven into new art forms. The extensive study of basic knowledge can make students get a variety of thinking modes and practical directions, and new artistic creation ideas and artistic expression ways will be produced through the integration of multiple disciplines. [1] Only when multiple disciplines are integrated can students really understand the content of digital, media and art. Digital media art specialty is the integration of digital, media and art knowledge and technology. The talent cultivation of digital media art specialty mainly includes the exploration and construction of interdisciplinary talents. Next, the author will focus on three aspects of digital media art specialty. Digital content mainly includes computer vision imaging, digital image processing, software, hardware, and interactive system and so on. Media content mainly refers to the understanding and practice of digital network platform, interactive program, digital equipment, virtual reality system and immersive system. Art content mainly include the content of design, art, film and television, animation and other aspects. The study of three aspects of knowledge and technology learning is very important for students to build professional understanding and application of digital media art. The talent training of digital media art specialty will be a new discipline constructed by many disciplines, and the interdisciplinary exploration and construction of discipline group is in line with the cultivation of compound talents. Therefore, the cultivation of 
interdisciplinary talents of digital media art specialty will involve the co-construction of teaching resources in different colleges and the need to promote the closer combination of schoolenterprise cooperation.

\section{THE BACKGROUND AND SIGNIFICANCE OF THE TRAINING OF INTERDISCIPLINARY TALENTS}

Since the 21st century, the fourth industrial revolution is based on the network physical system and integrates with digital technology in many fields. Digital information technology promotes the transformation of society and economy. In terms of economic structure, information technologyintensive economy replaces labor-intensive economy. Information technology-intensive industry is knowledge-intensive economy in essence. In recent years, such a change has become more and more clear, and has more and more obvious influence in the fields of work, study, life and education mode. The key to the transformation of knowledge-intensive society lies in the transformation of talents. The knowledge economy focuses on the comprehensive qualities of talents, such as excellent professional skills, certain abilities in other professional fields. This is the interdisciplinary talent what the society needs.

Today's social work is characterized by interdisciplinary integration, such as the integration of multi-disciplinary knowledge, the integration of a variety of work skills. With the social and economic development, the talent demand has affected the talent training at the educational level. The characteristics of the era of information integration have accelerated the development of many majors at multiple dimensions and perspectives. Colleges and universities gradually attach importance to the teaching concept of interdisciplinary infiltration, such as the interdisciplinary teaching of arts and science, engineering and science. This demand characteristic based on comprehensive ability determines the construction of interdisciplinary talents training system in colleges and universities. For example, the experimental art specialty of the experimental art college of the Central Academy of Fine Arts integrates anthropology, sociology, art, science and technology and other aspects to carry out interdisciplinary teaching and talent training. The department of information design in the Academy of Fine Arts of Tsinghua University integrates many professional resources in teaching, such as programming technology, art design, project management and so on. Interdisciplinary teaching of knowledge and skills has become an important direction of the development of higher education. Interdisciplinary penetration has become an important way to cultivate interdisciplinary talents, that is, to cultivate interdisciplinary talents with one specialty and multiple abilities, extensive knowledge reserve, comprehensive ability of knowledge penetration, practical ability of multiple skills, speculative and innovative ability. It is to meet the needs of compound and innovative talents under the national economic development in the 21 st century. This is a new subject of higher education research, such as traditional advantage discipline, new discipline, innovative talent training and so on. Digital media art specialty is a related specialty developed with the development of the digital era. It is a product of the digital era. Therefore, the talent training of digital media art specialty needs to keep up with the needs of the times in order to construct a valuable new discipline and talent training program. [2] Media art specialty involves a variety of disciplines and technologies, so the construction of teaching content of digital media art specialty should pay attention to the needs of social and economic development and the change of technology. In particular, the development of the fields related to digital media is faster, and the change speed of new function is faster. Therefore, the talent training of digital media art specialty should pay attention to building a teaching framework with enterprises. And then, the teaching content can be constantly improved in practice. For colleges, it is suggested to constantly update the relevant laboratory equipment and teaching content, so as to achieve the purpose of teaching. Then, both colleges and enterprises should be built around the teaching.

For digital media art specialty, the effective construction of school-enterprise cooperation is an important guarantee of high-quality curriculum, and it is also a new requirement of the development of the times for talent demand. Although the construction and development of digital media art specialty in colleges and universities in China has experienced a period of accumulation, they can build an effective curriculum group. Generally speaking, the development of digital media art is still in the stage of exploration and experimental construction, so private colleges and universities should pay more attention to the cultivation of 
digital media art professionals, which is an important opportunity.

\section{EFFECTIVE EXPLORATION OF INTERDISCIPLINARY TALENTS TRAINING}

The interdisciplinary is a comprehensive combination of theories and methods of different majors, that is, a reasonable, effective and scientific discipline group formed and proved in the longterm practice. The process of interdisciplinary theory and practice is also the process of the emergence of new specialty. The training mode of interdisciplinary talents is a talent training mode of higher education which is based on the demand for interdisciplinary talents formed by the social and economic development since the 1980s and meets the needs of the era. For example, by taking the second degree or minoring in other majors, students can obtain the basic knowledge and skills of many majors other than their own, so as to become a versatile talent who can adapt to interdisciplinary research and work. In such majors as experimental art, digital media art, science and technology art and cross media art, there is an interdisciplinary core. For example, after five years of experimental teaching exploration, China Academy of Fine Arts has built a cross-media art specialty (code: 130408TK). Adhering to the requirements of talent cultivation, this major takes crossover interaction as the basic idea, pays equal attention to art, science and technology and humanities education, and interacts with each other, promoting the interdisciplinary research and cross-field practice of contemporary art. The interdisciplinary research of cross-media art specialty of the China Academy of Fine Arts is an important model of Chinese art teaching. After more than 10 years of exploration and practice, the school of cross-media has formed a teaching system based on multidisciplinary research, teaching and creation. Such a teaching system is undoubtedly experimental and pioneering. After more than 10 years of verification, it has also proved that it is effective. The scientific teaching system brings more possibilities and opportunities for students' employment and entrepreneurship, enabling students to better adapt to the changes in the entire society and the demand for innovative talents and compound talents. The cross-media school integrates and develops creative teaching models in various aspects such as technology, culture, art, anthropology, performance, sound, video, installation, etc., thus laying a foundation for the new power and new innovation model of crossmedia art. Another example is the experimental art specialty of the Central Academy of Fine Arts, which focuses on the experimental and forwardlooking aspects of academic research and creative practice. Such forward-looking nature will inevitably strengthen the social needs in the context of interdisciplinary and promote the exploration of the potential of cross-media performance. Interdisciplinary experimental synthesis is an important way to explore and construct the training system of interdisciplinary talents. The cultivation of experimental art specialty constructs the interaction and interconnection of science and technology, society and experiment on the teaching content. The experiment spirit integrates the content of science and technology and the content of social humanities. The art of science and technology is supported by the spirit of experimental exploration. In this way, it can form mutual supporting forces in the historical background of the development of digital economy and cultivate high-quality interdisciplinary talents. These two majors based on interdisciplinary research have formed an innovative talent training system after more than 10 years of exploration, and are constantly improving and perfecting in the trend of the times. [3] The interdisciplinary exploration and practice of these two majors is of great reference significance to the exploration and practice of interdisciplinary talents cultivation of arts in other universities. The development of science and technology art specialty is undoubtedly a discipline constructed by repositioning the major of digital media art. The construction and development of this major mainly integrates with the talent training mode based on the discipline groups of science and technology and art. Interdisciplinary exploration and improvement is adjusted with the change of social economy. At present, the knowledge framework of digital media art specialty mainly includes several subject groups: the related courses of digital media art theory centered on the introduction of digital media art, the interactive software course group centered on programming, the art curriculum group based on animation, image and design, and the management curriculum group based on project management. These curriculum groups together construct interdisciplinary and compound talent training. Introduction to digital media art enables students to realize the development process of digital media art. Animation, video and other art courses enable students to have the aesthetic concept and ability. Programming and other interactive software courses enable students to get the ability and 
technical support to practice the new aesthetic concept. Management courses enable students to understand the management process, steps and project implementation of digital media art projects. These courses construct the important content of interdisciplinary talents' ability in the process of mutual independence and connection. Through the analysis of multiple related interdisciplinary majors, it is suggested to clearly realize that interdisciplinary teaching is an effective exploration of interdisciplinary talents training. In the following, this paper will analyze the construction of interdisciplinary talents from several aspects.

\section{EFFECTIVE CONSTRUCTION OF THE TRAINING SYSTEM OF INTERDISCIPLINARY TALENTS}

\subsection{The Interdisciplinary Specialty Setting Should Meet the Requirements of Social and Economic Development}

For the training of interdisciplinary talents, it is required that the specialty setting should be combined with the needs of social development, market demand and employment position as the guidance, and the creative talents should be cultivated in combination with the resources inside and outside the university. For example, the open media system of cross-media school of China Academy of Fine Arts closely follows the internationalization of high-tech art creation, emphasizing the current unique network social ecology. Professional research settings include VR, $\mathrm{AR}$, mobile phone art, real-time dynamic art, program art, etc. Interdisciplinary specialty setting can cultivate and train students' practical ability and knowledge thinking ability to adapt to social and economic development. Another example is the emerging discipline. The new technology emphasized by the major of science and technology art has covered many fields, such as interactive art, media art, data art, biological art, ecological art, intelligent manufacturing, new material application, etc. A new round of technological revolution and industrial revolution is developing. As an interdisciplinary subject of art education, science and technology art is facing the new requirements of social development. Science and technology art specialty will become a new engine of social innovation, which aims to cultivate interdisciplinary talents with both art and technology. With the development of information technology, digital media art specialty is a related art specialty, so the courses taught by digital media art specialty are in line with the needs of new jobs generated by social and economic development. Nowadays, digital economy is the breakthrough of China's economic transformation, and as a national strategy, it has penetrated into more subdivided economic industries. Intelligent technology, Internet, interactive systems and other high-end industries are the products of the deep integration of the new generation of information technology and economic society, and they are the important engines to promote China's social and economic development. Digital media art specialty combines Internet technology, web design, interactive design, multimedia equipment, digital information processing technology and other contents to construct courses and train talents. [4] In addition, it is also required to establish school-enterprise cooperative relations, and be carried out in teaching forms, such as workshops, experimental classes and practical training. Each college in a university has its own professional advantages, so it can use the teaching resources of different colleges to build interdisciplinary course. For example, UI design course can be used as the interdisciplinary course of digital media art and information management. "The cultivation of interdisciplinary talents based on the integration of art and industry needs the research and development and concrete construction of "cross-college cooperation courses".

\subsection{The Formulation of Talent Training Program Is Combined with Interdisciplinary Discipline}

Professional training program is not only the guiding program of higher education, but also the important basis and main framework of professional teaching. Interdisciplinary talent training requires students to have interdisciplinary knowledge and theoretical structure, multiple professional skills and practical ability. The setting of interdisciplinary courses takes into account the professional skills and knowledge in various fields to meet the needs of social economy. The reasonable setting of interdisciplinary courses is beneficial to the construction of innovative talent training system. [5] For example, the new media art direction of the information design department of the Academy of Fine Arts of Tsinghua University is a new discipline of information technology and art interaction. In the interdisciplinary field of art and information science, it is suggested to expand students' innovation ability, thinking interaction ability and planning ability, and cultivate 
interdisciplinary talents with comprehensive qualities of humanities, art, science and technology. The talent training program of digital media art specialty is to develop interdisciplinary content. During the development of digital media art specialty, there are also some questions, such as the formulation of talent training program. Talent training programs for digital media art specialty and related majors such as animation, video and broadscreen editing will produce similar discussions. The courses involved in digital media art specialty include video, film and television content, animation games, and editing and other related teaching contents, and it is easy to form a broad and inaccurate personnel training orientation in the personnel training program. As a result, the teaching content is the same as that of other majors, and the talent training orientation and goal of digital media art specialty are lost, resulting in some problems in the talent training. First of all, in the first aspect, it is necessary to clearly know that the talent training of digital media art specialty is based on the requirements of interdisciplinary integration to cultivate interdisciplinary talents, which is a comprehensive and interdisciplinary training mode. Therefore, it will involve the knowledge and skills of different disciplines when establishing the curriculum. The talent training system of digital media art enables to integrate the three aspects of digital, media and art innovatively.

\subsection{Constructing the Interdisciplinary curriculum system of public basic courses and Elective Courses}

Curriculum system is the organic combination mode of many different courses. Different curriculum systems shape the knowledge structure and development mode of talents. Each professional direction takes its own curriculum system as the fixed mode. After the specialty refinement, the curriculum system may limit the free development of students, and may also hinder the possibility of the school's own innovative running and characteristic development. With the development of interdisciplinary interaction in recent years, the interdisciplinary curriculum system is more conducive to the construction of comprehensive knowledge system. Different courses of different disciplines learn from each other and optimize each other, realizing the intersection and complement of major and elective courses, and achieving the advantage complementation among different disciplines. There are not only common basic courses, but also interdisciplinary and differentiated elective courses. The interdisciplinary curriculum system of public basic courses and elective courses realizes the training framework of one specialty and multiple abilities. It not only respects students' individual needs and development, but also effectively cultivates students' ability of integrating knowledge construction and innovation. [6] In addition, the coordination among public courses, elective courses and professional courses is primary and secondary. Students can fully learn the knowledge of multiple disciplines in a limited time, and the relationship between knowledge network and knowledge structure will be formed. For example, the construction of public courses in digital media art specialty can be co-constructed with other professional teaching resources, such as animation courses, basic design courses, film and television courses, etc. Elective course is another important part of professional courses. To effectively supplement elective courses, it is required to set up more innovative courses and more cutting-edge courses. For example, in the elective course of digital media art specialty, artificial intelligence and human engineering can be incorporated into the content of the elective course, and their cuttingedge nature can be integrated into the existing teaching framework system, so as to cultivate students' awareness of keeping up with the changes of the times in the professional field.

\subsection{The Setting of Interdisciplinary Teaching Content and the Innovation of Teaching Methods}

At present, there are some contradictions in professional talent training program and professional curriculum. Interdisciplinary curriculum is easy to dilute the content of professional curriculum, and multidisciplinary curriculum is also easy to cause the complexity and confusion of subject knowledge structure. Therefore, the setting of interdisciplinary teaching content should consider the reasonable and scientific curriculum content of subject group formed by years of teaching and learning. On the other hand, the teaching content cannot be limited to the content of the major, and the limitation of single teaching content cannot achieve the cultivation of interdisciplinary talents. In addition, for the cultivation of interdisciplinary talents, it is necessary to pay attention to the organic combination of theoretical teaching and practical teaching, the trinity of production, study and research, and the combination of laboratory and 
practice base. The information-based multimedia teaching method has the advantages of being multidimensional, multi-perspective, hyperlink and cross-media. When selecting teaching materials, it is necessary to have a broad international vision, the core of the spirit of the times, the use of national teaching materials for the 21 st century, the national unified compilation of teaching materials, planning teaching materials. For example, in the framework of the original talent training program, digital media art specialty will combine new media and new types of digital industry to set new curriculum contents. For example, in recent two years, with the development of artificial intelligence, the application of big data has also affected the artistic creation of digital media. Therefore, the basic knowledge of artificial intelligence is also included in the teaching content of digital media art specialty. "The construction of science, technology and art innovation laboratory" is in line with the development needs of the new generation of digital cultural and creative industries, and is in line with the mode of crosscollege curriculum cooperation and co-construction of art disciplines and science and engineering disciplines. For example, the interactive design course and the virtual reality design course should be based on the new classroom of the science and technology and art innovation laboratory through the way of cross-college cooperation. Also, it is necessary to be closely around the teaching of the science and technology and art innovation laboratory, so as to realize the cultivation of the interdisciplinary talents of "art and technology" and "art and science".

\subsection{The Construction of "Interdisciplinary" Teaching Staff}

With the continuous evolution of the information society, the social demand for interdisciplinary teachers is also increasing. In such a changing situation of social development, private application-oriented colleges and universities should keep up with the new requirements of education innovation, and constantly strengthen the construction of "interdisciplinary" teaching staff based on the demand of talent cultivation under the influence of market economy development. "Interdisciplinary" teachers mainly refer to those who are specialized in multiple abilities, have cross-professional education background or teaching background, and can engage in professional teaching and teaching of related majors. To a certain extent, there is a lack of "interdisciplinary" teaching staff in private universities. However, through the comprehensive discipline construction, discussion and training, effective resource integration can be achieved. There are many ways for teachers to improve their comprehensive quality. For example, teachers of digital media art specialty should not only have the basic knowledge of art painting and design ability, but also need to have the ability to use software and project management ability. The ability of digital media art teachers needs to be multi-faceted. And they should be able to design ideas, use software, and apply programs. For example, 3D software is used to make animation, and video editing software is used to edit and integrate 3D animation or special effects. Finally, it can combine with interactive software to make interactive and immersive works of art. The ability to connect and integrate multiple fields is what teachers of digital media art specialty need to have in artistic creation, scientific research and project creation. [7] People with these abilities need interdisciplinary knowledge and skills. Only with this ability can we create and teach new media art well. In the training of digital media art teachers, they also need to pay attention to the practical training ability in related fields or enterprises. Therefore, the enterprise training of digital media art teachers is the key and effective. Through the training of teachers in enterprises in related fields, it can cultivate the comprehensive ability of teachers with one specialty and multiple abilities. And a variety of skills and abilities can be combined to complete complex work.

\section{CONCLUSION}

With the development of social economy and industrial transformation, social development gradually increases the demand for interdisciplinary talents. The interdisciplinary infiltration is an effective way to explore the training system of interdisciplinary talents in digital media art specialty. This paper further explores and constructs the training system of interdisciplinary talents. In terms of specialty setting, it needs to meet the requirements of social and economic development. In the formulation of personnel training program, it is suggested to combine the characteristics of interdisciplinary disciplines. Innovation is also needed in the construction of curriculum system and teaching content, such as the construction of the teaching training mode of "science and technology and art innovation laboratory" and the training mode of "cross-college cooperation course". Finally, the cultivation of 
interdisciplinary talents also needs to pay attention to the construction of "interdisciplinary" teaching staff.

\section{AUTHORS' CONTRIBUTIONS}

Wencai Lin wrote the manuscript and contributed to revising. Yuyuan Zhou contributed to editing.

\section{REFERENCES}

[1] Jiao Lei. An Analysis of Interdisciplinary Development Trend of World-renowned Universities [J]. Research in Higher Education of Engineering, 2018, (3): 124-129. (in Chinese)

[2] Shen Yong, Zheng Chaonan. The connotation, characteristics and path exploration of interdisciplinary research [J]. Industrial \& Science Tribune, 2018, 17(2): 95-96. (in Chinese)

[3] Hu Lele. On the interdisciplinary reform of research universities under the background of "double first-class" [J]. Jiangsu Higher Education, 2017, (4): 42-47. (in Chinese)

[4] Wang Kaiyou. A Preliminary Study on the Cultivation of Compound Talents in Normal Universities [J]. Journal of Anqing Normal University (Social Science), 2000, (5): 92. (in Chinese)

[5] Yang Hui, Chi Jianhui. The Exploration and Reflection of the Cultivation of Digital Media Art Talents in the Production-Education Context - A Case Study of Changzhou VoTech College of Information [J]. Educational Theory and Practice, 2015(36). (in Chinese)

[6] Li Qiang, Luo Tian, Wang Jingjing. Teaching reform and exploration of digital media under the background of new engineering subjects [J]. 2020(S1). (in Chinese)

[7] Liang Zheng, Zhang Yuhong. Virtual reality technology and digital media art teaching $[\mathrm{J}]$. 2021(03). (in Chinese) 